\title{
Inflammatory Pseudotumor of the Spleen: A Case Report
}

\section{Kaushal Anand*}

Surgical Gastroenterologist and HPB, Shailya Hospital, India

"Corresponding author: Kaushal Anand, Head, Surgical Gastroenterologist and HPB, Shailya Hospital, India, Tel: +91 9727722700; E-mail:

dr_kaushalanand@yahoo.co.in

Received date: Apr 04, 2017; Accepted date: Apr 14, 2017; Published date: Apr 26, 2017

Copyright: (c) 2016 Anand K. This is an open-access article distributed under the terms of the Creative Commons Attribution License, which permits unrestricted use, distribution, and reproduction in any medium, provided the original author and source are credited.

\begin{abstract}
An inflammatory pseudotumor of the spleen is a rare benign disease with unknown etiology which requires a differentiation from the lymphoproliferative lesion of the spleen. A clinical presentation, preoperative imaging does not help to establish the diagnosis or rule out malignant potential, so the only diagnostic and therapeutic option is splenectomy along with histopathological and immunohistochemical analysis. We report a case with review of the literature.
\end{abstract}

Keywords: Inflammatory pseudotumor; Spleen; Langerhans cell histiocytosis

\section{Introduction}

Inflammatory pseudotumor is a benign disorder mainly occurs in respiratory system, liver, central nervous system and gastrointestinal tract. Spleen is a rare organ of presentation with only $\sim 75$ cases reported till date. It's a benign disorder of unknown origin presents as a reactive, inflammatory lesion within the organ and usually not diagnosed preoperatively. We present a case of splenomegaly with pyrexia of unknown origin.

\section{Case Report}

A 24 year female from Bihar, India referred to our department with history of pain in left hypochondrium for the past six months and pyrexia of unknown origin for the last one month. The pain was mild to moderate, continuous, dull aching not associated with vomiting, altered bowel habits and not requiring injectable analgesia. The fever was low grade not associated with chills or night sweats responding to antipyretics. Patient did not have anorexia or weight loss. On examination-no pallor, no peripheral lymphadenopathy. A non-tender moderate splenomegaly, no hepatomegaly, no free fluid in peritoneal cavity. Hemogram showed Hb: 9.6 g\%, Total leukocyte count 4500/ $\mathrm{cmm}$, Platelet count $1.05 \mathrm{lac} / \mathrm{cmm}$. Ultrasonography abdomen: splenomegaly with $7 \times 7 \times 8 \mathrm{~cm}$ heteroechoiec space occupying lesion in the lower pole with calcifications and central hypo echoic component s/o necrosis. Multiple gall stones present. CECT abdomen showed a $10 \times 7 \mathrm{~cm}$ mass with lobulated outline, hyperdense in noncontrast films with central hypo dense component. On contrast enhanced film central hypodense component with peripheral lobulated heterogeneous enhancing mass lesion seen (Figure 1).

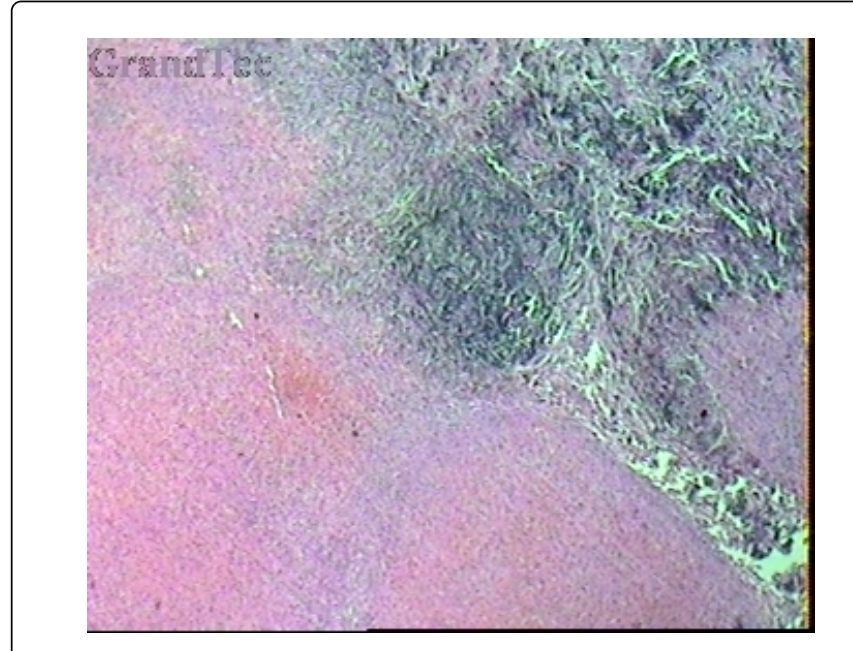

Figure 1: The Photomicrograph shows the border of the mass on upper right and normal splenic tissue on lower left (Haematoxylin and Eosin Stain $400 \times$ magnification).

With no evidence of systemic involvement patient underwent a splenectomy with cholecystectomy as diagnostic and therapeutic measure. The histopatholgical examination revealed inflammatory pseudotumor of spleen.

The surgical specimen of spleen measuring $16 \times 11 \times 5.5 \mathrm{~cm}$ with unremarkable outer surface. Cut surface showed a circumscribed lesion of $8 \times 6.5 \mathrm{~cm}$ grossly reaching up to capsule. The cut surface of the lesion was nodular, yellowish to grayish appearance with central stellate scar (Figure 2). 


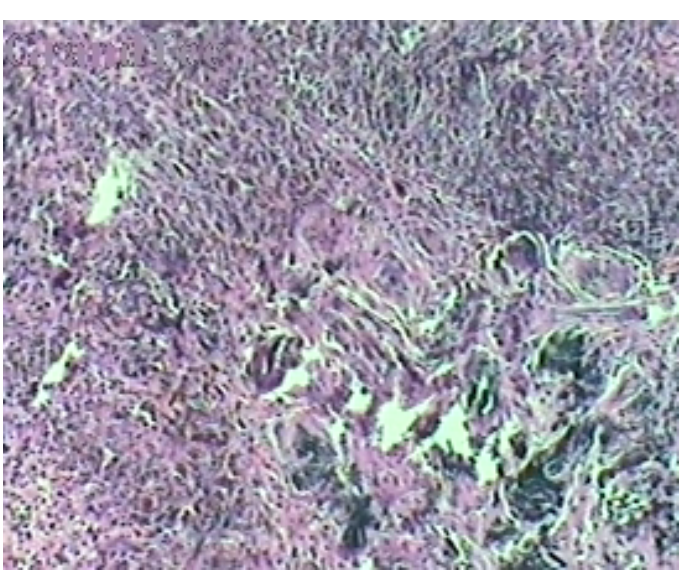

Figure 2: The lesion comprise of an aggressive looking heterogeneous mass of fibroblasts and spindle shaped histiocytes with hemosiderin deposition and associated reactive inflammatory cells like lymphocytes, eosinophil and plasma cells (Haematoxylin and Eosin Stain 1000× magnification).

Rest of the parenchyma unremarkable. On microscopic examination, lesion composed of cells displaying oval to oblong vesicular nuclei with intended and folded nuclear contours and moderate amount of pale cytoplasm. These cells are admixture with fair numbers of eosinophils, plasma cells and sparse lymphocytes. Areas of hemorrhage, hemosiderin deposition. Hyalinization and calcification are evident within the lesion (Figure 3).

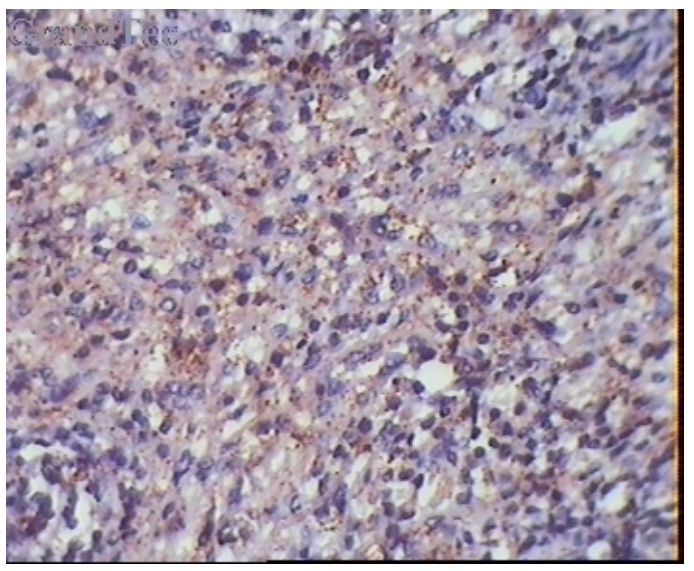

Figure 3: The CD 68 Immunostain shows diffuse cytoplasmic positivity for the spindle shaped fibroblasts (Immunoperoxidase stain, counterstained with haematoxylin $1000 \times$ magnification).

Immunohistochemistry revealed focal positivity of S-100, CD68 and vimentin. The lesional cells do not express CD34, smooth muscle actin and leukocyte common antigen is negative. The findings suggestive of inflammatory pseudotumor of spleen. This entity has been reported to be associated with proliferation of follicular dendritic cells in some cases.

Post-surgery course was uneventful and patient was discharged on 4th day.
She continued to have followed up with complete recovery and no constitutional symptoms till date (Follow up four months).

\section{Discussion}

Inflammatory pseudotumor (IPT) is a rare, benign lesion of unknown etiology most commonly present in respiratory system and very rare in spleen. It also found in liver, spinal cord, orbit, digestive system, heart, soft tissue [1]. It has been first described by Contelingam and Jaffe in 1984 and only 75 cases reported till date [2].

Clinical presentation varies from incidental to nonspecific symptoms (abdominal pain, fever etc.). Our patient presented with PUO and abdominal pain, she initially investigated for malaria, kala azar unremarkable, usg abdomen showed a heteroechoiec lesion in lower half of spleen and evaluated by CECT. Plain films showed lobulated well demarcated mass in lower half of spleen with central hypo density and peripheral calcification with hypodense lesion. On late contrast enhanced films showed delay enhancement of peripheral lesion with persistent central hypo density-s/o necrosis [3] MRI was not done but it can show hypo dense or is intense images on T1 films and enhancement on T2 images. Differentiation from malignant splenic lesion like lymphoma is not possible by preoperative images only. IPT is usually single but multiple lesions also have been reported [4].

Gross pathological features showed a circumscribed lesion of $8 \times 6.5$ $\mathrm{cm}$ grossly reaching up to capsule. The cut surface of the lesion was nodular, yellowish to grayish appearance with central stellate scar. Ultra structurally tumor consisted of plasma cells, lymphocytes, histiocytosis and fibroblasts with abundant collagen. Immunohistochemistry stains documented that the spindle cells were positive for vimentin. The most common feature with IPT is spindle cell proliferation admixed with inflammatory cells, mostly plasma cells and lymphocytes as seen in our case also. Hemosiderine deposits and calcification is also not unusual [5].

The pathogenesis of this tumor is not clear. An aberrant or exaggerated response to tissue injury without an established cause has generally been favored as the pathogenesis of the inflammatory pseudotumor or IMT [6]. Epstein-Barr virus infection and Clonal origin of tumor is showed with e/o aberration of chromosome 2p23, not evaluated in our case [6]. Many synonyms, such as inflammatory myofibroblastic tumor (IMT), plasma cell granuloma and inflammatory myofibroblastoma have been described. Follicular dendritic cell tumor is an extremely rare malignant neoplasm with microscopic features similar to IPT. It does show positivity for CD 35 with atypia and severe mitosis which is not present here [6].

Splenectomy remains the diagnostic and therapeutic procedure. Laparoscopic approach is feasible only if preoperative diagnosis of IPT is confirmed which is reported in only one case report [7]. Splenectomy is curative and no recurrence or adjuvant treatment require for the same. Post-operative course remained uneventful.

\section{Conclusion}

Inflammatory pseudotumor of spleen is rare benign lesion difficult to differentiate preoperatively from other malignant lesion and splenectomy is the diagnostic and therapeutic aid to it. 


\section{References}

1. Lee S, Park S, Jang JY, Kim SW, Park YH (2000) A Case Report of Inflammatory Pseudotumor in the Spleen. Korean J Hepatobiliary Pancreat Surg 4: 253-255.

2. Chen WH, Liu TP, Liu CL, Tzen CY (2004) Inflammatory pseudotumor of spleen. J Chin Med Assoc 67: 533-536.

3. Hiroyuki I, Hiroshi H, Kuniyuki K, Toshiro K, Tatsuro F (1996) Inflammatory Pseudotumors of the Spleen: CT and MRI Findings. Journal of Computer Assisted Tomography 20: 244-248.

4. Mcmohah RF (1988) Inflammatory pseudotumor of spleen, J Clin Pathol 41: 734-736.
5. Loshii SO, Sakamoto DG, Machuca TN, Yatani R (2004) Inflammatory pseudotumor of the spleen concomitant with renal cell carcinoma: case report. Sao Paulo Med J: 122.

6. Marina B, David MV, Feliciano, Majmudar B (2001) Pathologic Quiz Case: A Mass of the Spleen Archives of Pathology and Laboratory Medicine: 125: 1607-1608.

7. Hiroki U, Masayuki O, Kohei S, Yuichi E, Kentaro I (2006) Laparoscopic Splenectomy in Patients With Inflammatory Pseudotumor of the Spleen: Report of 2 Cases and Review of the Literature. Surg Laparosc Endosc Percutan Tech 16: 182-186. 